\title{
Cognitive-behavioral intervention via interactive multimedia online video game for active aging: study protocol for a randomized controlled trial
}

\author{
Fernando L. Vázquez ${ }^{1 *}$ D , Ángela J. Torres², Patricia Otero ${ }^{3}$, Vanessa Blanco ${ }^{4}$, Lara López ${ }^{1}$,
} Antonio García-Casal ${ }^{1}$ and Manuel Arrojo ${ }^{5}$

\begin{abstract}
Background: Due to the progressive aging of the population, programs to promote active aging have been recommended. However, older adults have difficulty accessing them. Interventions administered through online video games may increase their accessibility, and complementing these with a smartphone app will likely increase adherence and allow for ongoing professional monitoring. The objective of this study is to evaluate the efficacy of a cognitive-behavioral intervention for active aging administered through an online interactive multimedia video game that includes a smartphone app companion. The secondary objectives are to analyze the moderators and mediators of the change in the outcome variables and to evaluate the adherence to the intervention.

Methods/design: A randomized controlled clinical trial will be conducted. Adults 45 years and older will be randomly assigned to a cognitive-behavioral intervention administered through an online multimedia video game that includes a smartphone app companion or to a control group that will receive online information on active aging (274 participants per group). The intervention will be administered in eight weekly 45-min modules. An investigator-blinded evaluation will be conducted using online self-administered tests at baseline, post-intervention, and 6- and 12-month follow-ups. The primary outcome will be mental health status as evaluated using the 36-item Short-Form Health Survey (SF-36) at post-intervention. Secondary outcomes will be emotional well-being, depressive symptoms, reinforcement, negative thoughts, self-reported memory, cognitive task performance, sleep hygiene behaviors, physical activity, eating habits, body mass index, social support, dropout, treatment adherence, and satisfaction with the intervention.

Discussion: If the results are favorable, this study would involve the development of the first evidence-based active aging promotion intervention based on a video game that includes a smartphone app companion, providing evidence on its efficacy, accessibility, and clinical utility.
\end{abstract}

Trial registration: ClinicalTrials.gov, NCT03643237. Registered 27 August 2018.

Keywords: Older adults, Video game, Active ageing, Health promotion, Study protocol

\footnotetext{
* Correspondence: fernandolino.vazquez@usc.es

'Department of Clinical Psychology and Psychobiology, University of

Santiago de Compostela, Santiago de Compostela, Spain

Full list of author information is available at the end of the article
}

(c) The Author(s). 2019 Open Access This article is distributed under the terms of the Creative Commons Attribution 4.0 International License (http://creativecommons.org/licenses/by/4.0/), which permits unrestricted use, distribution, and reproduction in any medium, provided you give appropriate credit to the original author(s) and the source, provide a link to the Creative Commons license, and indicate if changes were made. The Creative Commons Public Domain Dedication waiver (http://creativecommons.org/publicdomain/zero/1.0/) applies to the data made available in this article, unless otherwise stated. 


\section{Background}

In Europe, the average age of the general population is increasing, with $19.1 \%$ over the age of 65 and $39.2 \%$ over the age of 50 [1]. Among the most common mental disorders in these age groups are depression and dementia [2], which are associated with high social and health costs [3, 4]. Moreover, these costs are expected to continue to increase, given that the percentage of people over the age of 65 in Europe will increase to $28.7 \%$ by 2080 (an increase of approximately 10 percentage points) [5]. As a result, the World Health Organization (WHO) [2] has emphasized the importance of programs promoting active aging with the goal of increasing the number of healthy and independent elderly people. In addition, the WHO recommends prescribing healthy lifestyles, such as physical activity and a balanced diet, to prevent diseases and preserve physical and mental faculties [6].

However, the lack of social and health care services for older adults, especially in rural areas [7], which tend to have more elderly people [8], may limit access to health preventive programs targeting key areas such as depression, cognitive decline, and unhealthy eating habits. One way to overcome these barriers and offer a program of active aging in an attractive way is through online video games. Video games are inexpensive, fun, and can be accessed from home at convenient times [9-11]. Furthermore, middle-aged and older adults are now more digitally connected than ever. Eighty-five percent of people ranging in age from 45 to 64 years and $67.8 \%$ of people aged 65 years and older have a computer with an Internet connection [12]. In addition, $80.3 \%$ of people ranging in age from 45 to 64 years, $59.0 \%$ of $65-69$ year olds, and $49.0 \%$ of 70-74 year olds have their own smartphone [13]; and this is just the beginning, since the number of older people with technological skills will even increase in the future. There is evidence supporting the effectiveness of video games in the general population for mental health [14], health promotion [9, 15], and the improvement of health-related outcomes [16]. Video game-based psychological interventions have been shown to be effective for the treatment of specific phobias [17] and depression [18] in young and middle age adults. However, the effectiveness of video games for active aging in adults from middle to late adulthood has received very little attention in the literature.

A meta-analysis comprising 21 randomized controlled trials about video game-based interventions aimed at healthy adults older than 44 found that video gamebased interventions produced positive effects on objectively measured physical health, negative affect, and social health, with small to small-to-medium effect sizes $(d=$ $0.34, d=0.26$, and $d=0.40$, respectively) [19]. However, these interventions have not been built on current knowledge of psychological science nor are they based on theoretical models. In addition, none of the interventions were based on a manualized treatment and few were based on a protocol, which limits the generalizability of the interventions. There was a wide use of non-standardized measures, and follow-ups were scarce.

In addition, there are few studies on serious video games or programs with gaming features aimed to promote behavior change and/or health [20], and they were only focused on cognitive training. There was only one video game for the prevention of depression in older people [21] and the games directed at physical condition have focused on balance and action [22]. None of the games have targeted developing a habit of physical activity and they have ignored other fundamental aspects related to health such as diet. Furthermore, none of the aforementioned studies integrated the components of mood, cognitive stimulation, and healthy life habits in the same intervention, despite the fact that a review of modifiable risk factors for dementia estimated that $51 \%$ of population-attributable risk was associated, among other factors, with depression, cognitive inactivity, physical inactivity, and midlife obesity; and these midlife risk factors could be tackled early to prevent or delay the onset of dementia [23]. In addition, none of the studies used a story or narrative thread in the video game, despite the fact that immersion in the history of the game can facilitate change of behaviors related to health [24] and that video games with storylines might be preferred by the elderly [25].

Finally, these studies had dropout rates of up to $25 \%$ [19] and reported insufficient playing time, a potential reason for lack of efficacy of video game-based interventions [15]. Thus, an additional device (such as a smartphone app) that complements the video game by sending reminders in real time and that allows for a follow-up by a clinical professional could help increase adherence to the intervention and the generalization of the video game to real life (i.e., using the skills learned in the video game in daily real life situations beyond the gaming sessions).

\section{Aims and hypothesis}

The main objective of the randomized controlled trial is to evaluate the efficacy of a cognitive-behavioral intervention to promote active aging in a holistic manner (incorporating mental health status, emotional well-being, depressive symptoms, self-reportd memory, healthy habits, and social support). The intervention will be administered through a serious online interactive multimedia video game with a complementary smartphone app. The intervention group will be compared to a control group that will have access to online information. 
The secondary objectives are to analyze the moderators and mediators of the change in the outcome variables and to evaluate the adherence with the intervention. As a central hypothesis, the intervention is expected to significantly improve mental health status compared to the control group. In addittion, intervention is expected to improve emotional well-being, depressive symptoms, self-reported memory, sleep hygiene behaviors, physical activity, eating habits, body mass index, and social support. As secondary hypotheses, it is expected that (a) the baseline values on sociodemographic variables, emotional well-being, depressive symptoms, self-reported memory, sleep hygiene behaviors, physical activity, eating habits, body mass index, and social support will moderate the effects of the intervention, and that reinforcement, negative automatic thoughts and cognitive task performance will mediate the effects of the intervention, (b) the experimental group will show a lower percentage of dropouts and higher satisfaction than the control group, and (c) cognitive task performance and treatment adherence will be higher than $50 \%$.

\section{Methods/design}

\section{Design}

A randomized controlled clinical trial will be conducted. The study protocol is in accordance with the Standard Protocol Items: Recommendations for Interventional Trials (SPIRIT) guidelines (see checklist in Additional file 1). Participants will be randomly assigned to: (a) an experimental group (EG) that will receive a cognitivebehavioral intervention administered through a serious online interactive multimedia video game with a complementary smartphone app for active aging (CBI-V) or (b) a control group (CG) that will receive online information on active aging.

The stages of the study are shown in Fig. 1. A combination of interviewer-based and self-report measures will be administered at pre-intervention, post-intervention (assessment will be performed at the end of the intervention, i.e., from 8 to 16 weeks after the beginning of the intervention), 6- and 12-months follow-up.

\section{Participants \\ Recruitment}

The research team of the University of Santiago de Compostela and the Ramón Domínguez Foundation will recruit the study participants from the population of people aged 45 years and over through clinics and health centers in the Autonomous Community of Galicia (Spain). Galicia is a region in the northwest of Spain with an area of $29,434 \mathrm{~km}^{2}$ and a population of 2,730,337 inhabitants (of whom two-thirds live in councils of less than 50,000 inhabitants) and it has the second oldest population in Spain [26]. Interested persons will be contacted and they will be given a brief description of the study. If they meet the inclusion criteria, they will be invited to participate in a complete evaluation that will include an interview by independent evaluators to ensure the lack of mental disorders and assess their cognitive status to adhere to the exclusion criteria. In addition, they will complete an online evaluation that will include the assessment of sociodemographic characteristics, mental health status, emotional well-being, depressive symptoms, reinforcement, negative thoughts, self-reported memory, sleep hygiene behaviors, physical activity, eating habits, body mass index, and social support by means of self-administered instruments. The potential participants will be asked to give their written informed consent before being randomly assigned to a study group.

\section{Eligibility criteria}

To participate in the study, participants will be required to (a) live in the Autonomous Community of Galicia, (b) be 45 years or older, (c) have the appropriate devices to play the game (computer, Smartphone and Internet connection), (d) give written consent to participate in the study, and (e) commit to complete the program and subsequent evaluations. We will exclude those participants who (a) have serious medical or mental disorders (e.g., depression, schizophrenia, bipolar disorder, major neurocognitive disorder, dissociative disorders, substance dependence or abuse), (b) have sensory, physical, or mental problems that make it impossible to complete the study (e.g., mild neurocognitive disorder, severe visual or auditory impairment), (c) have received psychological or psychopharmacological treatment in the last 2 months, and (d) are participating in another study.

\section{Randomization}

Stratified randomization by age groups will occur after screening and baseline assessments. Specifically, the age groups are 45-64 and $\geq 65$ years old, consistent with Levinsons' life cycle theory [27]. An independent researcher (allocation concealment) will make random allocation cards using computer-generated random numbers. The original random allocation sequences will be kept by the independent researcher in an inaccessible third place and the researcher will work with a copy. The randomization sequence will be communicated to the researchers by means of sealed numbered envelopes, one for each participant, with instructions to use them in numerical order. However, participants cannot be blinded to their treatment allocation due to the nature of the interventions.

\section{Sample size calculation}

Assuming a two-tailed test, $\alpha$ of 0.05 , a power $(1-\beta)$ of 0.80 , and a proportion of subjects in each group of 0.5 , we estimated that a sample size of 253 participants per 


\begin{tabular}{|c|c|c|c|c|}
\hline \multirow[b]{2}{*}{ TIMEPOINT } & \multicolumn{4}{|c|}{ STUDY PERIOD } \\
\hline & $\begin{array}{c}\text { Pre- } \\
\text { intervention } \\
\end{array}$ & $\begin{array}{c}\text { Post- } \\
\text { intervention }\end{array}$ & $\begin{array}{l}6 \text { months } \\
\text { follow up }\end{array}$ & $\begin{array}{l}12 \text { months } \\
\text { follow up }\end{array}$ \\
\hline \multicolumn{5}{|l|}{ ENROLMENT: } \\
\hline \multirow{3}{*}{$\begin{array}{r}\text { Eligibility screen } \\
\text { Written informed consent } \\
\text { Allocation }\end{array}$} & $\mathrm{X}$ & & & \\
\hline & $\mathrm{x}$ & & & \\
\hline & $\mathrm{X}$ & & & \\
\hline \multicolumn{5}{|l|}{ INTERVENTIONS: } \\
\hline \multicolumn{5}{|l|}{$\begin{array}{r}\text { Cognitive-behavioral intervention } \\
\text { administered through online } \\
\text { multimedia video game }+ \text { app }\end{array}$} \\
\hline Control Group & $\longleftarrow$ & $\longrightarrow$ & & \\
\hline \multicolumn{5}{|l|}{ ASSESSMENTS: } \\
\hline Sociodemographic characteristics & $\mathrm{x}$ & & & \\
\hline \multirow{2}{*}{$\begin{array}{r}\text { Diagnostic Interview } \\
\text { Cognitive function }\end{array}$} & $\mathrm{X}$ & & & \\
\hline & $\mathrm{x}$ & & & \\
\hline \multirow{2}{*}{ Mental health status } & $\mathrm{x}$ & $\mathrm{x}$ & $\mathrm{x}$ & $\mathrm{X}$ \\
\hline & $\mathrm{X}$ & $\mathrm{X}$ & $\mathrm{X}$ & $\mathrm{X}$ \\
\hline $\begin{array}{l}\text { Emotional well-being } \\
\text { Depressive symptoms }\end{array}$ & $\mathrm{x}$ & $\mathrm{X}$ & $\mathrm{X}$ & $\mathrm{X}$ \\
\hline Reinforcement & $\mathrm{X}$ & $\mathrm{X}$ & $\mathrm{X}$ & $\mathrm{X}$ \\
\hline \multirow{2}{*}{$\begin{array}{r}\text { Negative automatic thoughts } \\
\text { Self-reported memory }\end{array}$} & $\mathrm{X}$ & $\mathrm{x}$ & $\mathrm{X}$ & $\mathrm{x}$ \\
\hline & $\mathrm{x}$ & $\mathrm{X}$ & $\mathrm{X}$ & $\mathrm{X}$ \\
\hline Cognitive tasks performance* & $\longmapsto$ & $\rightarrow$ & & \\
\hline Sleep hygiene behaviors & $\mathrm{X}$ & $\mathrm{x}$ & $\mathrm{X}$ & $\mathrm{X}$ \\
\hline \multirow{2}{*}{$\begin{array}{r}\text { Physical activity } \\
\text { Eating habits }\end{array}$} & $\mathrm{X}$ & $\mathrm{x}$ & $\mathrm{X}$ & $\mathrm{X}$ \\
\hline & $\mathrm{X}$ & $\mathrm{X}$ & $\mathrm{X}$ & $\mathrm{x}$ \\
\hline Body Mass Index & $\mathrm{X}$ & $\mathrm{X}$ & $\mathrm{X}$ & $\mathrm{X}$ \\
\hline \multirow{2}{*}{$\begin{array}{r}\text { Social support } \\
\text { Dropout and treatment adherence } * *\end{array}$} & $\mathrm{x}$ & $\mathrm{x}$ & $\mathrm{x}$ & $\mathrm{x}$ \\
\hline & $\leftarrow$ & & & $\rightarrow$ \\
\hline \multirow{2}{*}{ Client satisfaction } & & $\mathrm{x}$ & & \\
\hline & \multicolumn{4}{|c|}{ As needed throughout the study } \\
\hline Adverse events & \multicolumn{4}{|c|}{ As needed throughout the study } \\
\hline
\end{tabular}

Fig. 1 SPIRIT figure. Phases of the randomized controlled trial

group will be required to detect a small effect size of 0.25 . This effect size is the minimum needed to reach meaningful clinical change and is consistent with the smallest effect size found in a previous meta-analysis of video gamebased interventions for active aging [19]. Specifically, an effect size of 0.26 for the mood outcome in active aging video game-based interventions was the smallest effect size identified [19]. To safeguard against an estimated $8 \%$ attrition rate [19], a minimum of 274 in each group must be recruited, which means 548 participants in total (550 approximately).

\section{Ethics}

The study procedures follow the principles of the Declaration of Helsinki and have been approved by the Bioethics Committee of the University of Santiago de Compostela (Spain). Any significant amendment to the protocol will have to be approved by the Committee prior to its implementation. Participation is voluntary, without incentives of any kind, and all participants will give their written informed consent. If a mental disorder is detected during any evaluation, the participant will be contacted to explain the finding and a referral to appropriate care will be provided. Consistent with the inclusion/exclusion criteria, the participant will be excluded from the study. After the completion of the study, any necessary or requested post-trial ancillary care will be attended and managed by the steering committee.

A comprehensive attempt will be made to measure adverse events. Participants will be asked to report adverse events by phone as soon as possible after they have occurred. Any adverse effects (muscle pain, visual fatigue, etc.) during the study will be recorded on a standardized adverse event form by the staff member and reported to the study coordinator. Subsequently, adverse events will be reported to the steering committee, who will take the necessary steps and provide details in the final report of the study. 


\section{Interventions}

The EG intervention will be administered through a serious online interactive multimedia video game and the CG materials through online readings. The same software and the same content will be administered to all the participants assigned to the same condition, which guarantees homogeneity in the application and increases the internal validity of the study. All participants will be trained in a 30 -min session and will receive a personalized instruction booklet with illustrations about how to log on to the online platform and how to report technical problems. The EG will be shown how to play the game and the CG will be shown how to access the active aging information within the platform.

\section{Cognitive-behavioral intervention administered through online interactive multimedia video game with smartphone- based app companion}

The EG intervention will be administered through a serious online interactive multimedia video game on a computer and a complementary smartphone-based app. The app allows the extension of the user's training, monitoring their progress and sending reminders in real time, as well as sending feedback to the clinicians about their progress. The contents have been designed by a team of expert psychologists from the University of Santiago de Compostela (Spain) and the video game has been developed by the informatic and telecommunications solutions companies Imatia Innovation, Sivsa Informatic Solutions, and Gradiant (Spain).

The intervention will be delivered based on a standardized treatment manual. The intervention consists of eight modules of approximately $45 \mathrm{~min}$ each. The modules will be administered at a rate of one per week with between-session homework to practice the trained skills in real life. The modules can also be administered one every two weeks if the participant needs more time to complete the homework. Thus, the intervention can last between 8 and 16 weeks. The video game is a graphic adventure, with a narrative thread or story that involves the player's experience and depicts a story, based on the French Way of St. James (i.e., the pilgrimage road from Roncesvalles -France- to the cathedral of Santiago de Compostela -Spain-).

The intervention consists of three components: prevention of depression, cognitive stimulation, and promotion of healthy lifestyle habits (sleep, physical activity, and diet). The prevention of depression component was adapted from an indicated-prevention intervention for depression based on the multi-factorial etiopathogenic model of depression by Lewinsohn et al. [28]. This intervention has been shown to be effective in the prevention of new episodes of major depression and in the reduction of depressive symptoms in the short and long term in both face-to-face format $[29,30]$ and by telephone multiconference [31]. The cognitive stimulation component of the intervention is based on the notion of "brain reserve" [32] and the concept of "cerebral neuroplasticity" [33] and is based on the model of cognitive stimulation developed by Spector et al., including mental stimulation, seeking new ideas, thoughts, and associations, and using hints and implicit learning [34, 35]. In addition, possible causes of memory deficits associated with aging are considered in the intervention: decreases in processing resources, lack of semantic coding, metamemory problems, and difficulties in the deliberate retrieval of information [36]. Finally, the promotion of healthy lifestyle habits component is based on learning theory and social cognitive theory [37], through which many human behaviors are learned via observation by way of attention, retention, production, and motivation. The change in behavior is a function of the state of skill development and confidence (self-efficacy) in performing the new behavior, with modeling, self-control strategies, goal setting, and feedback fundamental techniques for learning [38].

As shown in Table 1, throughout the intervention, the main character (Jacob) walks along the French Way of St. James meeting different characters that teach him different techniques to encourage changes that promote well-being and increase quality of life. In the first module, the concept of depression and the need for active coping for depressive symptoms are explained, and diaphragmatic breathing is also introduced. The second module focuses on increasing pleasant activities and self-reinforcement. From the third to the fifth module, participants are introduced to healthy sleep habits, physical activity, and healthy eating and given guidelines for implementing healthy habits. In the sixth and seventh modules, participants are trained in the identification of cognitive distortions and cognitive restructuring. The eighth module focuses on self-esteem and relapse prevention. Cognitive stimulation, social skills, self-efficacy, and a sense of control are transversal content to all modules.

\section{Online information control group}

Participants in the control group will have access to an online platform that contains material with general nonspecific information on active aging, structured in eight modules of approximately $45 \mathrm{~min}$ each at a rate of one per week. In particular, the information will cover general information related to aging, depression, cognitive deterioration, healthy lifestyle habits such as physical exercise, sleep, and balanced nutrition, and social relationships, but without guidelines for implementing them. There will be no training of specific psychological techniques and no homework assignments between sessions. 
Table 1 Content of the video game-based cognitive-behavioral intervention for active aging

\begin{tabular}{|c|c|c|c|}
\hline Module/component & Narrative & Techniques and strategies & App companion support \\
\hline $\begin{array}{l}1 \\
\text { Mental health, } \\
\text { cognitive stimulation }\end{array}$ & $\begin{array}{l}\text { From Roncesvalles to Pamplona } \\
\text { Presentation of the main character (Jacob) } \\
\text { and start of the trip. Jacob is at a stage in } \\
\text { which he feels older, tired, sad, does not } \\
\text { sleep or eat properly, does not perform } \\
\text { physical exercise. } \\
\text { He starts the French Way of St. James to find } \\
\text { the peace he needs. An old man invites him } \\
\text { to take a book to guide him through the } \\
\text { stages. The book will show him the way and } \\
\text { will give him knowledge to reach his } \\
\text { personal goal. To begin, it explains the } \\
\text { relationship between our behaviors, } \\
\text { thoughts, and emotions. He meets Txomin, } \\
\text { who teaches him to monitor his emotions }\end{array}$ & $\begin{array}{l}\text {-Presentation of the protagonist and The } \\
\text { Way. } \\
\text {-Active aging: importance of emotional, } \\
\text { physical, and cognitive well-being for } \\
\text { healthy active aging. } \\
\text {-Mental health: explanation of mood } \\
\text { problems and the need for active coping for } \\
\text { optimal mental health; mood state diary. } \\
\text {-Healthy habits: training in relaxation } \\
\text { (diaphragmatic breathing) through } \\
\text { modeling. } \\
\text {-Cognitive stimulation: mnemonic strategies, } \\
\text { verbal and visual memory tasks. } \\
\text {-Social skills, assertive communication. }\end{array}$ & $\begin{array}{l}\text {-Review of what has been } \\
\text { learned. } \\
\text {-Map of the path: shows } \\
\text { progress and places and } \\
\text { significant learning at this } \\
\text { stage of the trip. } \\
\text {-Homework (with reminder } \\
\text { notifications). } \\
\text { - Mood tracking (self-report). } \\
\text { - Practice relaxation } \\
\text { (diaphragmatic breathing } \\
\text { technique). } \\
\text {-Trophies: can be obtained } \\
\text { through adherence and weekly } \\
\text { compliance with tasks. }\end{array}$ \\
\hline
\end{tabular}

Mental Health, cognitive stimulation

3

Mental Health cognitive stimulation sleep habits
Mental Health, cognitive stimulation, physical activity and a group of pilgrims who teach him a relaxation technique. He must pass through challenges (microgames of cognitive stimulation) to continue the path He meets the first illustrious pilgrims (e.g., Jean de Brienne), historical figures (e.g., King Alfonso II, Isabel the Catholic), and visits places of interest along the way: Albergue de Roncesvalles, Puente de Zubiri, Albergue Casa Paderborn.

From Pamplona to Estella

He meets the legend of the Source Reniega. Belfegor appears (minion of Lucifer) and tries to snatch the book. The Apostle James comes to his defense. Jacob is attacked and falls unconscious and in dreams he performs a challenge in order to continue on his way. He gets the indication to search and find nine groups of emotional vitamins in the road symbols (scallops); to get hold of them, he must pass several challenges (microgames of cognitive stimulation). Another pilgrim teaches him the value of self-reinforcement and how to put it into practice.

He visits places of interest along the way: Source Reniega, Alto del perdón, Brigde and Square de Puente la Reina, Church and hospital of pilgrims of Estella.

From Estella to Nájera

Jacob does not sleep well. He is tired, but various characters like Hirobumi and other pilgrims give him guidelines to improve his sleep habits. He is reunited with Txomin, who teaches him to plan pleasant activities and make contracts with himself. By doing this he declares, unknowingly, the war on Disnergia (fantastic character), who wants his book. In order to fight against her, he must get the cross of Tau, and to achieve it, he must solve microgames of cognitive stimulation. A battle with Disnergia takes place, and he expels her by performing a challenge

He visits places of interest along the way: Pamplona Park, Logroño.

From Nájera to Burgos

His mood is improving. Jacob and Guillen (another pilgrim who accompanies him throughout this stage of the journey and the next) are victims of the theft of the book by Disnergia and Morbilius (fantastic characters).
- Positive or corrective feedback of weekly homework compliance.

-Review of contents of Module 1. Long-term memory exercises.

- Mental health: effect of pleasant activities on mood, guidelines for identifying personal pleasant activities; selfreinforcement.

- Cognitive stimulation: mnemonic strategies, verbal fluency tasks, visual tracking, cancellation, ideomotor praxia, verbal and visuospatial short-term and working memory.

-Social skills, assertive communication.

-Positive or corrective feedback about the completion of the weekly homework.

- Review of contents of Module 2. Longterm memory exercises.

- Mental health: scheduling pleasant activities.

-Healthy sleep habits: discovering sleep hygiene guidelines.

-Cognitive stimulation: mnemonic strategies, verbal reasoning, working memory, executive functions (planning) and spatial orientation

-Social skills, assertive communication.

-Positive or corrective feedback about the completion of the weekly homework.

- Review of contents of Module 3. Longterm memory exercises.

Mental health: scheduling pleasant activities.
Previous and:

- List of personal pleasant activities.
Previous and:

- Perform the weekly pleasant activities schedule.
Previous and:

- Perform the plan to achieve the weekly goal of physical activity; self-monitoring and self-reinforcement. 
Table 1 Content of the video game-based cognitive-behavioral intervention for active aging (Continued)

\begin{tabular}{|c|c|c|}
\hline Module/component & Narrative & Techniques and strategies \\
\hline & $\begin{array}{l}\text { Templar monks help them chase them away } \\
\text { and give them physical activity guidelines to } \\
\text { stay in good physical condition. He must } \\
\text { solve puzzles to unlock information. The } \\
\text { confrontation with Disnergia takes place and } \\
\text { he defeats her doing a challenge, but not } \\
\text { Morbilius, who escapes. He recovers his } \\
\text { book. } \\
\text { He visits places of interest along the way: } \\
\text { Botanical park of La Rioja, Hayedo de Urrez, } \\
\text { San Juan de Ortega Church. }\end{array}$ & $\begin{array}{l}\text {-Physical activity: essential information and } \\
\text { intrinsic motivation (choosing personal value } \\
\text { statements to improve this area); setting of a } \\
\text { final goal and graduated subgoals; planned } \\
\text { action (what, with whom, when, where, and } \\
\text { how). } \\
\text {-Cognitive stimulation: verbal work memory, } \\
\text { executive functions (planning), ideational } \\
\text { praxia. } \\
\text { - Social skills, assertive communication. }\end{array}$ \\
\hline $\begin{array}{l}5 \\
\text { Mental health, } \\
\text { cognitive stimulation, } \\
\text { physical activity, } \\
\text { healthy eating habits }\end{array}$ & $\begin{array}{l}\text { From Burgos to Sahagún } \\
\text { The monks tell him that a wise man knows } \\
\text { how to defeat Morbilius. The book, after } \\
\text { conducting challenges (micropuzzles of } \\
\text { cognitive stimulation) gives clues about the } \\
\text { wise man and healthy eating patterns. They } \\
\text { go to a restaurant to eat, where they meet } \\
\text { the wise man and a woman (Venustea), but } \\
\text { Morbilius kidnaps her and takes the book } \\
\text { away, and they must help the wise cook by } \\
\text { taking memory challenges related to } \\
\text { information about food and memory. They } \\
\text { get objects that will help them fight against } \\
\text { Morbilius. They fight with Morbilius, save } \\
\text { Venustea and recover the book. Guillen }\end{array}$ & $\begin{array}{l}\text {-Positive or corrective feedback about the } \\
\text { completion of the weekly homework. } \\
\text { - Review of contents of Module 4. Long- } \\
\text { term memory exercises. } \\
\text {-Healthy eating habits: essential information } \\
\text { and intrinsic motivation (choosing personal } \\
\text { value statements to improve this area); } \\
\text { eating pyramid (food groups and frequency } \\
\text { intake); meal planning (portions and } \\
\text { cooking). } \\
\text { - Cognitive stimulation: mnemonic } \\
\text { strategies, visual and work memory, } \\
\text { ideomotor praxis, executive functions } \\
\text { (planning). } \\
\text { - Social skills, assertive communication. }\end{array}$ \\
\hline
\end{tabular}
decides to stay with Venustea and Jacob continues on his way.

He visits places of interest along the way: San Tirso de Sahagún Church.

Mental health, cognitive stimulation, physical activity, healthy eating habits

7

Mental health, cognitive stimulation, physical activity, healthy eating habits

Mental health, cognitive stimulation, physical activity, healthy eating habits

\section{From Sahagún to Rabanal}

The book provides an explanation of the thoughts and their influence on mood. He meets the architect Antón Gaudín (historical character), whom he helps rid of cognitive distortions by overcoming challenges. The book teaches him to identify and record their own negative thoughts. He visits places of interest along the way: Pantheon Museum of the Royal Collegiate of San Isidoro de León, Episcopal Palace of Astorga, Rabanal Hostel.

He finds a muleteer in his trip (a carrier of merchandise in a cart drawn by horses) when he is attacked by the cognitive distortions (minions of Lucifer). The muleteer, and later a Templar, teach him to substitute his negative and irrational thoughts for more rational and positive ones. Finally, Jacob helps the muleteer when he is attacked.

He visits places of interest along the way: El Bierzo, Ponferrada, O Cebreiro, Triacastela.

\section{From Triacastela to Santiago}

He meets again with the muleteer, who gives him a valuable object: the cognitero, similar to the botafumeiro that serves to keep the treasures of our mind. He is reunited with Hirobumi, who gives him the seed of the tree of self-esteem and teaches him how to strengthen it so that it grows healthy and strong. Txomin teaches him the priming technique to inject positive thoughts. Before reaching the goal, he fights

\section{From Rabanal to Triacastela}

-Positive or corrective feedback about the

- Review of contents of Module 5. Longterm memory exercises.

- Mental health: connection situationthoughts on mood; main cognitive distortions (e.g., overgeneralization); selfregistration of negative thoughts

- Cognitive stimulation: attention and concentration, language, verbal and visual memory, ideomotor praxia.

- Social skills, assertive communication.

-Positive or corrective feedback about the completion of the weekly homework.

- Review of contents of Module 6. Longterm memory exercises.

- Mental health: cognitive restructuring strategies (direct approach, the worst that could happen, opinion survey, how does this thought help?).

- Cognitive stimulation: attention, working memory, long-term memory, ideomotor praxia, cognitive functions (planning). - Social skills, assertive communication.

-Positive or corrective feedback about the completion of the weekly homework.

- Review of contents of Module 7. Longterm memory exercises.

- Mental health: techniques for managing thoughts (distraction, priming); self-esteem enhancement (identifying personal strengths and achievements).

-Cognitive stimulation: attention, ideomotor praxis, language, working memory, planning, long-term memory. completion of the weekly homework. thought-emotion; the effect of negative

App companion support

Previous and:

-Daily record of food intake.

- Healthy eating plan: changes according to three priority levels.

Previous and:

- Negative thought detection.

Previous and:

- Use of cognitive restructuring strategies record. 
Table 1 Content of the video game-based cognitive-behavioral intervention for active aging (Continued)

\begin{tabular}{lll}
\hline Module/component & Narrative & Techniques and strategies \\
\hline & the boss (Lucifer); all the characters whom & -Social skills, assertive communication. \\
& Jacob met along the way appear, contribut- & - Progress maintenance, farewell and closing. \\
& ing their teachings and thus helping to de- & \\
& feat Lucifer. Jacob makes an offering to \\
& Santiago, who gives him the Compostela (a \\
& document given to all pilgrims who \\
& complete the pilgrimage) in recognition for \\
& having completed the path and acquire \\
& healthy lifestyle habits. Jacob prepares him- \\
& self for a new life with more illusion; he \\
& knows himself better and has the strategies \\
& to live happier. \\
& He visits places of interest along the way: \\
& Monte del Gozo, Cathedral of Santiago de \\
& Compostela.
\end{tabular}

Note: Throughout the game, when participants pass each challenge they get points (positive reinforcement). The challenge gradually increases the level of difficulty

Thus, this comparison group controls for contextual and non-specific factors (e.g., receiving attention, using a technological device). This results in a conservative estimate of the effect of the treatment [39].

\section{Intervention adherence}

All study interviewers and staff will be provided with guidelines for communication with participants to establish a good rapport and to improve adherence to the study protocol. All participants will be given the contact details of the study coordinators and be instructed to communicate any difficulties they may experience or questions that may arise during the study. To minimize the loss of participants, we will follow the strategies recommended by Grady et al. [40]; that is, making the intervention accessible and conducting non-invasive, useful, and interesting evaluations. The data collected from participants who prematurely finish the study will be registered in a Termination Form.

\section{Outcome measures}

To evaluate if the participants meet the exclusion criteria, a diagnostic interview and an evaluation of cognitive function will be conducted. For the diagnostic interview, the Spanish version [41] of the Mini International Neuropsychiatric Interview [MINI]) [42] will be used; this is a structured diagnostic interview that explores the main mental disorders of Axis I of the DSM-IV or ICD-10. The MINI must be conducted by a clinician and has adequate validity and reliability [43]. Cognitive function will be assessed with the Spanish version [44] of the Mini-mental State Examination (MMSE) [45], which consists of 30 items, with norms adjusted for age and education, good reliability values, a sensitivity of $89.8 \%$, and a specificity of $75.1 \%$. The evaluation will be conducted face-to-face by trained interviewers who will not know the objectives of the study, what interventions will be administered, and randomization outcomes. The training of the evaluators will be conducted by two researchers with more than 20 years of experience in evaluation, and it will consist of $15 \mathrm{~h}$ of theoreticalpractical seminars and role-playing about the diagnostic interview and evaluation strategies.

The participants who meet the eligibility criteria will complete the self-administered instruments through a smartphone app, and the data will be automatically downloaded into a database. Assessments will be performed pre- and post-intervention (which will be performed at the end of the intervention; that is, 8 to 16 weeks after the beginning of the intervention) and at 6and 12-month follow-ups. Table 2 presents a synthesis of the variables, the measurement instruments, and the form of administration and Fig. 1 shows the timing for each outcome variable.

\section{Primary outcomes}

Mental health status (specifically at post-intervention) will be the primary outcome, measured with the Spanish version [46] of the 36-item Short-Form Health Survey (SF-36) [47]. This 36-item scale assesses perceived health in eight dimensions (general health, physical functioning, role-physical, bodily pain, vitality, social functioning, role-emotional, and mental health) and an item about declared health evolution, with internal consistency ranging from 0.71 to 0.94 [47] grouped in two or components (physical health and mental health) with an internal consistency of 0.94 and 0.89 , respectively [48]. The eight dimensions and the two components could be used as secondary outcomes or in exploratory analyses.

\section{Secondary outcomes}

Socio-demographic variables will be collected through a self-administered questionnaire that will include sex, age, marital status, social class, income, level of studies, 
Table $\mathbf{2}$ Overview of measures

\begin{tabular}{|c|c|}
\hline Instrument & Format \\
\hline \multicolumn{2}{|l|}{ Screening } \\
\hline Diagnostic interview: MINI & $\begin{array}{l}\text { Hetero-administered (face to } \\
\text { face) }\end{array}$ \\
\hline Cognitive function: MMSE & $\begin{array}{l}\text { Hetero-administered (face to } \\
\text { face) }\end{array}$ \\
\hline \multicolumn{2}{|l|}{ Participant characteristics } \\
\hline Socio-demographic characteristics & Self-administered (app) \\
\hline \multicolumn{2}{|l|}{ Primary outcomes } \\
\hline Mental health status: SF-36 & Self-administered (app) \\
\hline \multicolumn{2}{|l|}{ Secondary outcomes } \\
\hline Emotional well-being: GHQ-12 & Self-administered (app) \\
\hline Depressive symptoms: CES-D & Self-administered (app) \\
\hline Reinforcement: EROS & Self-administered (app) \\
\hline $\begin{array}{l}\text { Negative automatic thoughts: } \\
\text { ATQ }\end{array}$ & Self-administered (app) \\
\hline Self-reported memory: MMQ & Self-administered (app) \\
\hline Cognitive tasks & Registered automatically by app \\
\hline Sleep hygiene behaviors: SHI & Self-administered (app) \\
\hline Physical activity: BPAAT & Self-administered (app) \\
\hline Eating habits: REAP-S & Self-administered (app) \\
\hline Body mass index: BMI & Self-administered (app) \\
\hline Social support: Duke-UNC-11 & Self-administered (app) \\
\hline Dropout & Registered by researcher \\
\hline Treatment adherence & Registered automatically by app \\
\hline Client satisfaction: CSQ-8 & Self-administered (app) \\
\hline Termination form & Registered by researcher \\
\hline Adverse event form & Registered by researcher \\
\hline
\end{tabular}

Abbreviations: ATQ Automatic Thoughts Questionnaire, BMI body mass index, BPAAT Brief Physical Activity Assessment Tool, CES-D Center for Epidemiologic Studies Depression Scale, CSQ-8 Client Satisfaction Questionnaire, Duke-UNC-11 Duke-UNC Functional Social Support Questionnaire, EROS Environmental Reward Observation, GHQ-12 General Health Questionnaire, MINI Mini International Neuropsychiatric Interview, MMQ Multifactorial Memory Questionnaire, MMSE Mini-Mental State Examination, REAP-S Rapid Eating and Activity Assessment for Participants-Shortened Version, SF-36 36-Item ShortForm Health Survey, SHI Sleep Hygiene Index

main activity, and area of residence. Marital status, social class, income, level of education, main activity, and area of residence will be recoded as binary variables. Specifically, marital status will be categorized as single, with a partner; social class as low/middle-low/middle, middlehigh/high; income level as $\leq 1999 €, \geq 2000 €$; level of education as primary/secondary, university; main activity as domestic work/unemployed, employed; and area of residence as rural, urban. Emotional well-being will be measured using the Spanish version [49] of the General Health Questionnaire (GHQ-12) [50], consisting of 12 items, which is intended to screen for general (non-psychotic) psychiatric morbidity, whose internal consistency is
0.86 for people under 65 years and 0.90 for people aged 65 years and over. Depressive symptoms will be assessed with the Spanish version [51] of the Center for Epidemiologic Studies Depression Scale (CES-D) [52], consisting of 20 items and with a high internal consistency of 0.89 . Reinforcement of the environment will be assessed with the Spanish version [53] of the self-reported Environmental Reward Observation Scale (EROS) [54]. It consists of ten items in which the participant evaluates the degree of positive reinforcement received contingently from their environment. The internal consistency of the Spanish version is 0.86 . Negative automatic thoughts will be evaluated through the Spanish version [55] of the Automatic Thoughts Questionnaire (ATQ) [56]. This is a 30-item self-report questionnaire with an internal consistency of .96. Self-reported memory will be measured with the Multifactorial Memory Questionnaire (MMQ) [57], consisting of 57 items assessing three dimensions: contentment, ability and strategy. The MMQ has high internal consistency for its three subscales $(0.95,0.93$ and 0.83 respectively). The number of cognitive tasks completed in the video game will also be evaluated. Participants' sleep hygiene behaviors will be assessed with the Sleep Hygiene Index (SHI) [58], a 13-item instrument with internal consistency of 0.66. Participants' physical activity will be assessed with the Spanish version [59] of the Brief Physical Activity Assessment Tool (BPAAT) [60], a two-item test that classifies participants into sufficiently active or insufficiently active, with good test-retest reliability $(\mathrm{k}=0.70)$ and convergent validity with the International Physical Activity Questionnaire $(k=0.64)$ [61].

Eating habits will be assessed with the Rapid Eating and Activity Assessment for Participants-Shortened Version (REAP-S) [62]. This 16-item scale has good convergent validity with the Block Semi Quantitative Food Frequency Questionnaire ( $r$ from -0.384 to 0.506 ) [63] and is based on the Dietary Guide-lines of the US Department of Health and Human Services [64] and the Healthy People 2010 objectives ( $r$ from -0.039 to 0.516) [65]. Body mass index (BMI) is a measure for indicating body fat in adults. It is defined as an individual's weight in kilograms divided by the square of their height in meters $\left(\mathrm{kg} / \mathrm{m}^{2}\right)$. Body fat is classified as underweight, normal weight, pre-obesity, and obesity (I, II, and III) [66]. Social support will be assessed with the Spanish version [67] of The Duke-UNC Functional Social Support Questionnaire (Duke-UNC-11) [68], an 11-item test with high internal consistency (0.90). Dropouts and treatment adherence will be assessed. A record will be kept of the dropouts in each group throughout the study. In addition, adherence will be assessed through numbers of modules completed, time played, and between-session homework accomplishment. Adherence will be automatically 
registered and monitored through the online platform and the smartphone app companion.

Finally, satisfaction with the intervention will be assessed with the Spanish version [69] of the Client Satisfaction Questionnaire (CSQ-8) [70], an eight-item scale with an internal consitency of 0.80 .

\section{Data management}

The personal data and the clinical data of the participants will be coded and saved separately. The files of the participants will be stored in numerical order for a period of 5 years after the end of the study. All data will be entered into a database where the personal data of the individuals will not be recorded. Range checks and consistency checks against data already stored in the database will be made. All evaluation and hardware related to the study data will be kept in closed cabinets. Access to the study data will be restricted to researchers through a password system. A backup copy of the original database (primary database) will be made every 15 days. All reports and publications derived from the study will be prepared so that no participant can be identified.

\section{Statistical analyses}

We will use the SPSS statistical package for Windows (version 22.0) for the analysis of the data. All analyses will be carried out in accordance with a modified intention to treat principle. If a mental disorder is detected at post-intervention or any follow-up, the participant will be excluded from the study retrospectively [71]. If participants withdraw from the study or data are missing for another reason (e.g., incomplete questionnaires, exclusion after baseline participation due to the onset of a mental disorder), the lost values will be imputed using multiple imputation [72]. Multiple imputation will be based on predictors of the outcome, including auxiliary variables (i.e., sex, age, level of studies, income, main activity, emotional well-being, depressive symptoms, reinforcement, negative automatic thoughts, self-reported memory, sleep hygiene behaviors, physical activity, eating habits, body mass index, and social support) using chained equations and the number of imputations following recommendations of Buuren [73] and White et al. [74]: using the Bodner's approximation related to Fraction of missing information (FMI) they suggest the rule of thumb that $\mathrm{m}$ should be similar to the fraction of missing cases so $\mathrm{m}$ is selected based on FMI/ $\mathrm{m} \approx 0.01$. For $\mathrm{FMI}=0.05,0.1,0.2,0.3,0.5$ the required $m \geq 3,6,12,24,59$, respectively. For evaluating the severity of missing data problem (i.e., how much variability in parameter estimation is introduced by imputation) the relative increase in variance due to non-response, ratio $r$ [75], and the fraction of missing information, FMI or $\gamma$ parameter [73], will be estimated. Following recommendations of $\mathrm{Li}$ et al. [76], values for the FMI parameter of up to 0.2 will be interpreted as "modest", 0.3 as "moderately large", and 0.5 as "high". Futhermore, Graham's recommendations [77] for reducing biasing effects due to MNAR missing data will be followed. Therefore, auxiliary variables will be included, longitudinal missing data diagnostics will be conducted (i.e., examining the patterns of change over time), intent to drop out will be measured, and follow-up data from those missing will be collected, if possible. In addition, complete case analyses will be analyzed and will be presented in a sensitivity analysis.

To analyze the effect of the intervention on the outcome variables, linear mixed models (LMM) will be used $[78,79]$. Condition $x$ Time interaction will be analyzed through conditional F-test with degrees of freedom correction developed by Kenward and Roger [80]. When adjusting for multiple comparison the BenjaminiYekutieli false discovery rate-controlling method [81] will be used for controlling type I error. After fitting the LMM model, residual diagnostic and influence diagnostics of unusual values will be evaluated. The assumptions should be checked for within-group error as well as for random effects following the recommendations of Pinheiro and Bates [79]. If residual checking is not satisfactory in terms of presence of heterocedasticity, different variance structures should be checked. Problems related to non-normal residuals should be avoided by changing the distribution family or using Box-Cox transformations. If problems arise from the presence of dependence in correlation, the inclusion of an adequate correlation structure will be analyzed. The effect size will be calculated using the Cohen's $d$, interpreting values $d=0.20$ 0.49 as small, $d=0.50-0.79$ as medium, and $d \geq 0.8$ as large [82].

The impact of potential moderators which may influence the change in pre-/post-intervention and preintervention/12-month follow-up mental health will be explored with linear regression analyses. For evaluating potential moderator effects, the linear model regression proposed by Baron and Kenny [83] was applied: $O=\alpha+\beta_{1} T+\beta_{2} M+\beta_{3} T M$, where $O$ represents the outcome, $\mathrm{T}$ represents reception of treatment, $M$ represents the potencial moderator, and TM represents the interaction between treatment and potential moderator. Putative moderators will be baseline values of sex, age, level of education, emotional well-being, depressive symptoms, self-reported memory, sleep hygiene behaviors, physical activity, eating habits, body mass index, and social support. Variables will be centered following Kraemer and Blasey [84] recommendations. 
To analyze potential mediating variables, we will use differences in pre-/post-intervention and pre-intervention/ 12-month follow-up mental health as the dependent variable $(\mathrm{Y})$, the experimental condition received as the predictor $(\mathrm{X})$, and differences in pretest-post-test levels of reinforcement and negative automatic thoughts, as well as cognitive task performance as possible mediators $(\mathrm{M})$. We will fit three regression equations: $\mathrm{Y}=\alpha+\mathrm{cX}+\varepsilon$ (association between the predictor and the dependent variable); $\mathrm{M}=\alpha+\mathrm{aX}+\varepsilon$ (association between the predictor and the mediator); $\mathrm{Y}=\alpha+\mathrm{bM}+\mathrm{c}^{\prime} \mathrm{X}+\varepsilon$ (association between the mediator and the dependent variable controlling for the predictor). Following Hayes's recommendations [85], the mediation effect will be estimated as $c-c^{c}=a b$, and bootstrapping will be used to determine the significance of that value. The proportion of the total effect of the predictor in the dependent variable that can be explained by the mediators will be calculated using the formula $\left[\left(a b / a b+c^{\prime}\right) \times\right.$ 100.

Sex and level of education will be used as binary variables, body mass index as a categorical variable (underweight, normal weight, pre-obesity, and obesity); while age, emotional well-being, depressive symptoms, reinforcement, negative automatic thoughts, self-reported memory, cognitive task performance, sleep hygiene behaviors, physical activity, eating habits, social support, adherence, and satisfaction will be used as continuous variables.

Dropouts and adherence, as well as the level of satisfaction with the intervention, will be analyzed through frequency distributions. Characteristics of patients lost to follow-up will be analyzed and compared to patients who finish the interventions to search for any attrition bias.

\section{Monitoring}

A Data Monitoring Committee (DMC) independent of the organizers of the study formed by the Center for Industrial Technological Development will be established to monitor the correct execution of the study. This committee will be able to order independent audits once a year. The steering committee, directed by the principal investigator and consisting of representatives of Imatia, Sivsa, Gradiant, Ramón Domínguez Foundation, and the research team of the University of Santiago de Compostela, will follow the principles of good clinical practice, including quality control of the clinical protocol, the handling of the data, and the organization of the team meetings. A confidential annual report on the development of the trial will be sent to the DMC. An independent statistician will conduct interim analysis and inform the independent DMC, who will discuss the results of the analysis with the steering committee at a joint meeting. The steering committee will then decide on the continuation of the trial and report to the Bioethics Committee.

\section{Exit strategy}

An exit strategy will be implemented in the following situations: (1) A participant decides to exit the trial prematurely. In this case, a questionnaire to find out the reasons for exit will be carried out in a (voluntary) exit phone call. Staff involved in the project will make sure the project has come to a satisfactory closure and the participant feels comfortable with the situation. (2) The trial period has come to an end. From the beginning of the study, it will be made clear to the participant that the trial period is a maximum of 16 weeks of intervention plus 12 months of follow-up. Participants will also be prepared for transition and closure.

\section{Discussion}

In this study, the efficacy of a cognitive-behavioral intervention administered through an online interactive multimedia video game for active aging will be evaluated. Based on the results of previous studies from which the depression prevention component will be adapted [29-31], and on previous research on using video games to improve cognitive functions and promote healthy lifestyles in people of all ages $[9,20]$ and in older people [19], we expect to find an improvement in the mental health status, emotional and cognitive state, adoption of healthy lifestyle habits, and social support.

Previous randomized controlled trials on video gamebased interventions for older adults found positive effects on emotional well-being [86, 87], cognitive functioning $[88,89]$, and physical health [87, 90]. Although there have been no previous interventions to reduce the incidence of depression in adults through video games based on the model of Lewinsohn et al. [28], the efficacy of this model for reducing depressive symptoms and reducing the incidence of depression has been shown in face-to-face formats and telephone multiconferencing [29-31]. Improvements in specific cognitive areas have been reported in attention, visual memory, working memory, and processing speed [91] for video gamebased interventions. Similarly, previous research has found that video games for promoting healthy lifestyles have had an effect on the intention to change health behaviors [9], which are predictors of behavior change [92]. In addition, health interventions applied through video games have been shown to be as effective as other non-gamified interventions administered by computer [9].

The use of the video game format is justified for several reasons: (a) it includes characteristics such as images, sound, movement, and feedback that capture attention, the first step necessary for learning behaviors according to social cognitive theory [37]; (b) it is more attractive and rewarding than traditional face-to-face interventions [91]; (c) it increases intrinsic motivation [93], 
which is fundamental in the maintenance of health behaviors that entail some effort; (d) the immersion in the story allows the player to identify with the thoughts, emotions, and actions of the character of the video game, favoring commitment to intervention and changing attitudes and behaviors related to health [24]; (e) it provides the opportunity to plan behavioral changes and test them in a safe and relaxed environment [94]; (f) the immediate and concrete feedback provided by the video game reinforces the continued effort and keeps the player within a zone of proximal development [95], cultivating a persistent and optimistic motivational style [96]; and (g) the modeling and the repetitive nature of the video game favor learning and the acquisition of new behaviors [97].

Furthermore, the smartphone app complementary to the game is an innovation compared to previous video game-based interventions and may be a solution to attrition. The reminders sent to the user in real time may increase the completion of the homework, which has been shown to be a predictor of the outcome of the intervention $[98,99]$. In addition, previous research using interventions administered over the Internet has found that adding professional support improves the adherence and increases the effect size of interventions [100].

The strengths of this clinical trial include the inclusion of a comparison group with random assignment, investigator-blinded assessments, clear presentation of inclusion and exclusion criteria, valid diagnostic and assessment methods, adequate sample size to offer statistical power, and a clear description of statistical methods. Therefore, it has all the characteristics of the most rigorous studies, which involve a randomized, prospective clinical trial, called type I, according to Nathan and Gorman criteria [101]. In addition, the completion of between-session homework promotes the transfer and generalization of trained skills. Finally, the trial will be conducted in the community context, so that its results will have a higher level of generalization to the general population.

Following the recommendations of the National Institute of Mental Health Psychosocial Intervention Development Workgroup [102] and the New Freedom Commission on Mental Health [103], this alternative format to traditional face-to-face programs to administer psychological interventions will increase the accessibility of psychological interventions and will increase the tools of professionals to reach a greater number of people. The advantages of interventions administered through video games include anonymity, savings due to reduced travel time, the ability of the participant to choose the moment of application (eliminating waiting time and appointments), lower stigma involved in playing a video game instead of attending a conventional therapy, and low cost [96].
Although there is currently a proliferation of commercial video games for the promotion of health and some studies have researched their effects [104], in many cases they have been designed for entertainment and very few have proven their efficacy scientifically [96]. This study may help reduce the dangers associated with the lack of quality control of video games currently available, providing an evidence-based intervention to promote active aging.

This study will provide information on the efficacy of an intervention for active aging and explore the use of alternative formats to increase the accessibility of therapies. It is an innovative study that will change the way in which treatments are received and reach a greater number of potential users, including those who are least likely to be served in traditional service centers and formats. The results of this study will benefit a large number of current older people and even more in the future, as the number of older adults with technological skills continues to increase. Considering the high social and economic costs of depression and cognitive impairment $[3,4]$, the implications for public health are significant.

\section{Trial status}

Recruitment start: December 28, 2020.

Study completion: September 30, 2023.

\section{Supplementary information}

Supplementary information accompanies this paper at https://doi.org/10. 1186/s13063-019-3859-5.

Additional file 1. SPIRIT 2013 Checklist: Recommended items to address in a clinical trial protocol and related documents.

\section{Abbreviations}

ATQ: Automatic Thoughts Questionnaire; BMI: Body mass index; BPAAT: Brief Physical Activity Assessment Tool; CBI-V: Cognitive-behavioral intervention administered through an online interactive multimedia video game with smartphone-based app companion; CES-D: Center for Epidemiologic Studies Depression Scale; CG: Control group; CSQ-8: Client Satisfaction Questionnaire; DMC: Data Monitoring Committee; Duke-UNC-11: Duke-UNC Functional Social Support Questionnaire; EG: Experimental group; EROS: Environmental Reward Observation; GHQ-12: General Health Questionnaire; GPPAQ: General Practice Physical Activity Questionnaire; M.I.N.I.: Mini International Neuropsychiatric Interview; MMQ: Multifactorial Memory Questionnaire; MMSE: Mini-Mental State Examination; REAP-S: Rapid Eating and Activity Assessment for Participants-Shortened Version; SF-36: 36-Item Short-Form Health Survey; SHI: Sleep Hygiene Index

\section{Acknowledgements}

Our thanks to the spin-off of the University of Santiago de Compostela "Xuntos. Psychological and Psychiatric Care".

Protocol version: 1.1 (18 September 2019).

Recruitment status: Pending.

\section{Authors' contributions}

FLV is the principal investigator and wrote the design of the study and manuscript. PO is a member of the project group, will coordinate the study, and helped in designing the study and writing the manuscript. LL and AGC are members of the project group and helped in designing the study and writing the manuscript. AJT, VB, and MA are members of the project group 
and reviewed the manuscript. All authors read and approved the final manuscript.

\section{Funding}

The development of this protocol was funded by grant EXP - 00091195/ ITC20161137 from Center for Industrial Technological Development of Spain and the European Regional Development Fund, and grant 2018-PU054 from Department of Culture, Education and University Regulation. This funding source had no role in the design of this study and will not have any role during its execution, analyses, interpretation of the data, or decision to submit results.

\section{Availability of data and materials}

Researchers will report study results through publications. The data supporting these findings will be presented in the main publications, and the datasets used during the study can be obtained from the corresponding author on reasonable request.

\section{Ethics approval and consent to participate}

The human rights and the dignity of the study participants will be protected in accordance with the Declaration of Helsinki. The study procedures have been approved by the Bioethics Committee of the University of Santiago de Compostela (Spain). The confidentiality of all participants will be guaranteed. Participants will have to give their written informed consent, and the informed consent form has been approved by the Bioethics Committee of the University of Santiago de Compostela (Spain).

\section{Consent for publication}

Not applicable.

\section{Competing interests}

The authors declare that they have no competing interests.

\section{Author details}

${ }^{1}$ Department of Clinical Psychology and Psychobiology, University of Santiago de Compostela, Santiago de Compostela, Spain. ${ }^{2}$ Department of Psychiatry, Radiology, Public Health, Nursing and Medicine, University of Santiago de Compostela, Santiago de Compostela, Spain. ${ }^{3}$ Department of Psychology, University of A Coruña, A Coruña, Spain. ${ }^{4}$ Department of Evolutive and Educational Psychology, University of Santiago de Compostela, Santiago de Compostela, Spain. ${ }^{5}$ Department of Psychiatry, Instituto de Investigación Sanitaria (IDIS), Complejo Hospitalario Universitario de Santiago de Compostela, SERGAS, Santiago de Compostela, Spain.

\section{Received: 7 November 2018 Accepted: 26 October 2019}

\section{Published online: 09 December 2019}

\section{References}

1. Eurostat. Population data. 2017. http://ec.europa.eu/eurostat/data/ database?node_code=proj. Accessed 15 Apr 2018.

2. World Health Organization. Mental health and older adults. 2016. http:// www.who.int/mediacentre/factsheets/fs381/en/. Accessed 12 May 2018.

3. Farré M, Haro JM, Kostov B, Alvira C, Risco E, Miguel S, Cabrera E, Zabalegui A. Direct and indirect costs and resource use in dementia care: a crosssectional study in patients living at home. Int J Nurs Stud. 2016;55:39-49.

4. Sobocki P, Jönsson B, Angst J, Rehnberg C. Cost of depression in Europe. J Ment Health Policy Econ. 2006;9:87-98.

5. Eurostat. People in the EU: Who are we and how do we live? Luxembourg: Publisher is Publications Office of the European Union; 2015.

6. World Health Organization. MhGAP intervention guide for mental, neurological and substance use disorders in non-specialized health settings. Version 2.0. Italy: World Health Organization; 2016.

7. Bertolini P, Pisano E, Sivini S, Scaramuzzi S. Poverty and social exclusion in rural areas. Italy: European Commission. Directorate-General for Employment, Social Affairs and Equal Opportunities; 2008.

8. Eurostat. European-Comission. Rural development statistics by urban-rural typology. https://ec.europa.eu/eurostat/statistics-explained/index.php?title= Archive:Rural_development_statistics_by_urban-rural_typology\&oldid=2945 03. Accessed 24 Apr 2018.
9. DeSmet A, Van Ryckeghem D, Compernolle S, Baranowski T, Thompson D, Crombez $\mathrm{G}$, et al. A meta-analysis of serious digital games for healthy lifestyle promotion. Prev Med. 2014;69:95-107.

10. Ballesteros S, Prieto A, Mayas J, Toril P, Pita C, Ponce de León LP, et al. Brain training with non-action video games enhances aspects of cognition in older adults: a randomized controlled trial. Front Aging Neurosci. 2014;6:277.

11. Buitenweg JIV, van de Ven RM, Prinssen S, Murre JMJ, Ridderinkhof KR. Cognitive flexibility training: a large-scale multimodal adaptive active-control intervention study in healthy older adults. Front Human Neurosci. 2017;11:529.

12. U.S. Department of Commerce. Computer and internet use in the United States: 2016. https://www.census.gov/content/dam/Census/library/ publications/2018/acs/ACS-39.pdf. Accessed 22 June 2019.

13. Pew Research Center. Tech adoption climbs among older adults. https:// www.pewinternet.org/2017/05/17/technology-use-among-seniors/. Accessed 22 June 2019

14. Wilkinson N, Ang RP, Goh DH. Online video game therapy for mental health concerns: a review. Int J Soc Psychiatry. 2008;54:370-82.

15. Rahmani E, Boren SA. Videogames and health improvement: a literature review of randomized controlled trials. Games Health J. 2012;1:331-41.

16. Primack BA, Carroll MV, McNamara M, Klem ML, King B, Rich M, et al. Role of video games in improving health-related outcomes: a systematic review. Am J Prev Med. 2012;42:630-8.

17. Rothbaum BO, Hodges L, Smith S, Lee JH, Price L. A controlled study of virtual reality exposure therapy for the fear of flying. J Consult Clin Psychol. 2000:68:1020-6.

18. Shandley K, Austin D, Klein B, Kyrios M. An evaluation of 'Reach Out Central': an online gaming program for supporting the mental health of young people. Health Educ Res. 2010;25:563-74.

19. Vázquez FL, Otero P, García-Casal JA, Blanco V, Torres ÁJ, Arrojo M. Efficacy of video game-based interventions for active aging. A systematic literature review and meta-analysis. PLoS One. 2018;13:e0208192.

20. Fleming T, Cheek C, Merry SN, Thabrew H, Bridgman H, Stasiak K, et al. Serious games for the treatment or prevention of depression: a systematic review. Rev Psicopatol Psicol Clin. 2014;19:227-42.

21. Li J, Theng YL, Foo S. Exergames for older adults with subthreshold depression: does higher playfulness lead to better improvement in depression? Games Health J. 2016;5:175-82.

22. Howes SC, Charles DK, Marley J, Pedlow K, McDonough SM. Gaming for health: systematic review and meta-analysis of the physical and cognitive effects of active computer gaming in older adults. Phys Ther. 2017;97:1122-37.

23. Barnes DE, Yaffe K. The projected effect of risk factor reduction on Alzheimer's disease prevalence. Lancet Neurol. 2011;10:819-28.

24. Baranowski T, Buday R, Thompson DI, Baranowski J. Playing for real: video games and stories for health-related behavior change. Am J Prev Med. 2008:34:74-82.e10.

25. Torres ACS. Cognitive effects of video games on old people. Int J Disabil Hum Dev. 2011:10:55-8.

26. National Statistics Institute. Índice de envejecimiento por comunidad autónoma [Aging index by region]. http://www.ine.es. Accessed 26 Apr 2018.

27. Levinson DJ. A conception of adult development. Am Psychol. 1986;41:3-13.

28. Lewinsohn PM, Hoberman $H$, Teri L, Hautzinger M. An integrative theory of depression. In: Reiss S, Bootzin RR, editors. Theoretical issues in behaviour therapy. New York: Academic; 1985. p. 331-59.

29. Vázquez FL, Hermida E, Torres A, Otero P, Blanco V, Díaz O. Efficacy of a brief cognitive-behavioral intervention in caregivers with high depressive symptoms. Behav Psychol. 2014;22:79-96.

30. Vázquez FL, Torres Á, Blanco V, Otero P, Díaz O, Ferraces MJ. Long-term follow-up of a randomized clinical trial assessing the efficacy of a brief cognitive-behavioral depression prevention intervention for caregivers with elevated depressive symptoms. Am J Geriatr Psychiatry. 2016;24:421-32.

31. Vázquez FL, Torres Á, Otero P, Blanco V, Díaz O, Estévez LE. Analysis of the components of a cognitive-behavioral intervention administered via conference call for preventing depression among non-professional caregivers: a pilot study. Aging Ment Health. 2017;21:938-46.

32. Tucker AM, Stern Y. Cognitive reserve in aging. Curr Alzheimer Res. 2011;8: 354-60.

33. Shapiro M. Plasticity, hippocampal place cells, and cognitive maps. Arch Neurol. 2001;58:874-81.

34. Spector A, Thorgrimsen L, Woods RT, Orrell M. Making a difference: an evidence-based group programme to offer Cognitive Stimulation therapy (CST) to people with dementia. London: Hawker Publications; 2006. 
35. Aguirre E, Spector A, Streater A, Hoe J, Woods B, Orrell M. Making a difference 2: an evidence based group program to offer maintenance Cognitive Stimulation Therapy (CST) to people with dementia. London: Hawker Publications; 2014.

36. Light LL. Memory and aging: four hypotheses in search of data. Annu Rev Psychol. 1991:42:333-76.

37. Bandura A. Social foundations of thought and action: a social cognitive theory. Englewood Cliffs: Prentice-Hall, Inc; 1986.

38. Spiegler MD. Contemporary behavior therapy. Boston: Cengage Learning; 2016.

39. Gallin Jl, Ognibene FP. Principles and practice of clinical research. San Diego: Academic; 2012

40. Grady D, Cummings SR, Hulley SB. Alternative trial design and implementation issues. In: Hulley SB, Cummings SM, Browner WS, Grady DG, Newman TB, editors. Designing clinical research. Philadelphia: Lippincott Williams \& Wilkins; 2013. p. 151-70.

41. Ferrando L, Bobes J, Gibert J, Soto M, Soto O. MINI. Entrevista Neuropsiquiátrica Internacional. Versión en Español 5.0.0. DSM-IV. Madrid: Instituto IAP.

42. Sheehan DV, Lecrubier $Y$, Sheehan $\mathrm{KH}$, Amorim $P$, Janavs J, Weiller $E$, et al. The Mini-International Neuropsychiatric Interview (M.I.N.I.): the development and validation of a structured diagnostic psychiatric interview for DSM-IV and ICD-10. J Clin Psychiatry. 1998;59:22-33.

43. Sheehan DV, Lecrubier $Y$, Sheehan $\mathrm{KH}$, Janavs J, Weiller E, Keskiner A, et al. The validity of the Mini International Neuropsychiatric Interview (MINI) according to the SCID-P and its reliability. Eur Psychiat. 1997;12: 232-41.

44. Lobo A, Saz P, Marcos G, Día J, de la Cámara, Ventura T, et al. Revalidation and standardization of the cognition mini-exam (first Spanish version of the Mini-Mental Status Examination) in the general geriatric population. Med Clin. 1999;112:767-74.

45. Folstein MF, Folstein SE, McHugh PR. "Mini-mental state". A practical method for grading the cognitive state of patients for the clinician. J Psychiatr Res. 1975;12:189-98.

46. Alonso J, Prieto L, Antó J. La versión española del SF-36 Health Survey (Cuestionario de Salud SF-36): un instrumento para la medida de los resultados clínicos [Spanish version of SF-36 Health Survey: an instrument for measuring clinical outcomes]. Med Clin (Barc). 1995;104:771-6.

47. Ware JE Jr, Sherbourne CD. The MOS 36-item short-form health survey (SF36). I. Conceptual framework and item selection. Med Care. 1992;30:473-83.

48. Vilagut G, Valderas JM, Ferrer M, Garin O, López-García E, Alonso J. Interpretación de los cuestionarios de salud SF-36 y SF-12 en España: componentes físico y mental. [Interpretation of SF-36 and SF-12 questionnaires in Spain: physical and mental components]. Med Clin (Barc). 2008;130:726-35.

49. Rocha KB, Pérez K, Rodríguez-Sanz M, Borrell C, Obiols JE. Propiedades psicométricas y valores normativos del General Health Questionnaire (GHQ12) en población general española [Psychometric properties and normative values of the General Health Quationnnaire (GHQ-12) for Spanish population]. Int J Clin Health Psychol. 2011;11:125-39.

50. Golderberg D, Williams P. A user's guide to the General Health questionnaire. Windsor: NFER-Nelson; 1988.

51. Vázquez FL, Blanco V, López M. An adaptation of the Center for Epidemiologic Studies Depression Scale for use in non-psychiatric Spanish populations. Psychiatry Res. 2007;149:247-52.

52. Radloff LS. The CES-D scale: a self-report depression scale for research in the general population. Appl Psychol Meas. 1977;1:385-401.

53. Barraca J, Pérez-Álvarez M. Adaptación española del Environmental Reward Observation Scale (EROS) [Spanish adaptation of the Environmental Reward Observation Scale (EROS)]. Ansiedad Estrés. 2010;16:95-107.

54. Armento ME, Hopko DR. The Environmental Reward Observation Scale (EROS): development, validity, and reliability. Behav Ther. 2007:38:107-19.

55. Otero $P$, Vázquez FL, Blanco V, Torres A. Propiedades psicométricas de Cuestionario de Pensamientos Automáticos (ATQ) en cuidadores familiares. [Psychometric properties of the Automatic Thoughts Questionnaire (ATQ) in family caregivers.]. Behav Psychol. 2017;25:387-403.

56. Hollon SD, Kendall PC. Cognitive self-statements in depression: development of an automatic thoughts questionnaire. Cognit Ther Res. 1980;4:383-95

57. Troyer AK, Rich JB. Psychometric properties of a new metamemory questionnaire for older adults. J Gerontol B-Psychol. 2002;57:P19-27.
58. Mastin DF, Bryson J, Corwyn R. Assessment of sleep hygiene using the Sleep Hygiene Index. J Behav Med. 2006;29:223-7.

59. Puig A, Pena Ò, Romaguera M, Duran E, Heras A, Solà M, et al. Cómo identificar la inactividad física en atención primaria: validación de las versiones catalana y española de 2 cuestionarios breves [How to identify physical inactivity in primary care: validation of the Catalan and Spanish versions of 2 short questionnaires]. Aten Primaria. 2012;44:485-93.

60. Marshall AL, Smith BJ, Bauman AE, Kaur S. Reliability and validity of a brief physical activity assessment for use by family doctors. Br J Sports Med. 2005; 39:294-7.

61. Vuor I, Oka P, Stahl T. Promoting of health-enbancing physical activity. A preparatory European meeting. Tampere: UKK Institute; 1996.

62. Segal-Isaacson C, Wylie-Rosett J, Gans KM. Validation of a short dietary assessment questionnaire: the Rapid Eating and Activity Assessment for Participants short version (REAP-S). Diabetes Educ. 2004;30:774-81.

63. Block G. Invited commentary: comparison of the Block and the Willett food frequency questionnaires. Am J Epidemiol. 1998;148:1160-1.

64. Office of Disease Prevention and Health Promotion. Dietary guidelines for Americans. http://www.health.gov/dietaryguidelines. Accessed 5 Aug 2018.

65. U.S. Department of Health and Human Services. Healthy People 2010: understanding and improving health. 2nd ed. Washington, DC: U.S. Government Printing Office; 2000.

66. World Health Organization. http://www.euro.who.int/en/health-topics/ disease-prevention/nutrition/a-healthy-lifestyle/body-mass-index-bmi . Accessed 5 Aug 2018

67. Bellón JA, Delgado AS, Luna del Castillo JD, Lardelli P. Validity and reliability of the Duke-UNC-11 questionnaire of functional social support. Aten Primaria. 1996;18:153-63.

68. Broadhead W, Gehlbach SH, De Gruy FV, Kaplan BH. The Duke-UNC Functional Social Support Questionnaire. Measurement of social support in family medicine patients. Med Care. 1988;26:709-23.

69. Vázquez FL, Torres Á, Otero P, Blanco V, Attkisson CC. Psychometric Properties of the Castilian Spanish Version of the Client Satisfaction Questionnaire (CSQ-8). Curr Psychol. 2019;38:829-35.

70. Larsen DL, Attkisson CC, Hargreaves WA, Nguyen TD. Assessment of client/ patient satisfaction: development of a general scale. Eval Program Plann. 1979:2:197-207.

71. Fergusson D, Aaron SD, Guyatt G, Hébert P. Post-randomisation exclusions: the intention to treat principle and excluding patients from analysis. BMJ. 2002:325:652-4

72. Schafer JL. Analysis of incomplete multivariate data. New York: Chapman Hall; 1997.

73. Van Buuren S. Flexible Imputation of Missing Data. 2nd ed. Boca Raton: Chapman \& Hall/CRC Press; 2018.

74. White IR, Royston P, Wood AM. Multiple imputation using chained equations: issues and guidance for practice. Statistics Med. 2011:30:377-99.

75. Barnard J, Rubin D. Small-sample degrees of freedom with multiple imputation. Biometrika. 1999:86:948-55.

76. Li KH, Raghunathan TE, Rubin DB. Large-sample significance levels from multiply imputed data using moment-based statistics and an $\mathrm{F}$ reference distribution. J Am Stat Assoc. 1991;86:1065-73.

77. Graham JW. Missing data analysis: making it work in the real world. Annu Rev Psychol. 2009;60:549-76.

78. Jiang J. Linear and generalized linear mixed models and their applications. New York: Springer; 2007.

79. Pinheiro JC, Bates DM. Mixed-effects models in S and S-PLUS. New York: Springer; 2000.

80. Kenward $\mathrm{MG}$, Roger $\mathrm{JH}$. An improved approximation to the precision of fixed effects from restricted maximum likelihood. Comput Stat Data An. 2009;53:2583-95.

81. Benjamini $Y$, Yekutieli D. The control of the false discovery rate in multiple testing under dependency. Annals Stat. 2001;29:1165-88.

82. Cohen J. Statistical power analysis for the behavioral sciences. 2nd ed. New Jersey: Lawrence Erlbaum Associates; 1988.

83. Baron RM, Kenny DA. The moderator-mediator variable distinction in social psychological research: conceptual, strategic, and statistical considerations. J Pers Soc Psychol. 1986:51:1173-82

84. Kraemer HC, Blasey CM. Centring in regression analyses: a strategy to prevent errors in statistical inference. Int J Methods Psychiatr Res. 2004;13: $141-51$. 
85. Hayes AF. Beyond Baron and Kenny: statistical mediation analysis in the new millenium. Commun Mongr. 2009;76:408-20.

86. Nouchi R, Saito T, Nouchi H, Kawashima R. Small acute benefits of 4 weeks processing speed training games on processing speed and inhibition performance and depressive mood in the healthy elderly people: evidence from a randomized control trial. Front Aging Neurosci. 2016;8:302.

87. Schoene D, Valenzuela T, Toson B, Delbaere K, Severino C, Garcia J, et al. Interactive cognitive-motor step training improves cognitive risk factors of falling in older adults. A randomized controlled trial. PLoS One. 2015;10: e0145161.

88. Grönholm-Nyman P, Soveri A, Rinne JO, Ek E, Nyholm A, Neely AS, et al. Limited effects of set shifting training in healthy older adults. Front Aging Neurosci. 2017:9:69.

89. Souders DJ, Boot WR, Blocker K, Vitale T, Roque NA, Charness N. Evidence for narrow transfer after short-term cognitive training in older adults. Front Aging Neurosci. 2017;9:41.

90. Bacha JM, Gomes GCV, de Freitas TB, Viveiro LAP, da Silva KG, Bueno GC, et al. Effects of Kinect adventures games versus conventional physical therapy on postural control in elderly people: a randomized controlled trial. Games Health J. 2018;7:24-36.

91. Toril P, Reales JM, Ballesteros $S$. Video game training enhances cognition of older adults: a meta-analytic study. Psychol Aging. 2014;29:706-16.

92. Bartholomew Eldredge LK, Markham CM, Ruiter RA, Fernández ME, Kok G, Parcel GS. Planning health promotion programs: an intervention mapping approach. San Francisco: Jossey Bass; 2016.

93. Graesser A, Chipman P, Leeming F, Biedenbach S. Deep learning and emotion in serious games. In: Ritterfeld U, Cody M, Vorderer P, editors. Serious games: mechanisms and effects. New York: Routledge; 2009. p. 81-100.

94. Read JL, Shortell SM. Interactive games to promote behavior change in prevention and treatment. JAMA. 2011;305:1704-5.

95. Vygotsky LS. Mind in society: the development of higher psychological processes. London: Harvard University Press; 1980.

96. Granic I, Lobel A, Engels RC. The benefits of playing video games. Am Psychol. 2014;69:66-78.

97. Kato PM. Video games in health care: closing the gap. Rev Gen Psychol. 2010;14:113-21.

98. Kazantzis N, Deane FP, Ronan KR. Homework assignments in cognitive and behavioral therapy: a meta-analysis. Clin Psychol Sci Prac. 2000;7:189-202.

99. Otero P, Vázquez FL, Hermida E, Díaz O, Torres Á. Relationship of cognitive behavioral therapy effects and homework in an indicated prevention of depression intervention for non-professional caregivers. Psychol Rep. 2015; 116:841-54.

100. Andersson G, Cuijpers P. Internet-based and other computerized psychological treatments for adult depression: a meta-analysis. Cogn Behav Ther. 2009;38:196-205.

101. Nathan PE, Gorman JM. A guide to treatments that work. 3rd ed. New York: Oxford University Press; 2007

102. Hollon SD, Muñoz RF, Barlow DH, Beardslee WR, Bell CC, Bernal G, et al. Psychosocial intervention development for the prevention and treatment of depression: promoting innovation and increasing access. Biol Psychiatry. 2002:52:610-30

103. New Freedom Commission on Mental Health. Achieving the Promise: Transforming Mental Health Care in America, Executive Summary. Rockville: DHHS; 2003.

104. Goldstein J, Cajko L, Oosterbroek M, Michielsen M, Van Houten O, Salverda F. Video games and the elderly. Soc Behav Personal. 1997;25:345-52.

\section{Publisher's Note}

Springer Nature remains neutral with regard to jurisdictional claims in published maps and institutional affiliations.

Ready to submit your research? Choose BMC and benefit from:

- fast, convenient online submission

- thorough peer review by experienced researchers in your field

- rapid publication on acceptance

- support for research data, including large and complex data types

- gold Open Access which fosters wider collaboration and increased citations

- maximum visibility for your research: over $100 \mathrm{M}$ website views per year

At $\mathrm{BMC}$, research is always in progress.

Learn more biomedcentral.com/submissions 